\title{
Industrial 3D printing in Italy
}

\section{Luca Beltrametti and Angelo Gasparre*}

Department of Economics and Business Studies, University of Genoa,

Via Vivaldi, 5, 16126 Genoa, Italy

Email: luca.beltrametti@economia.unige.it

Email: angelo.gasparre@economia.unige.it

*Corresponding author

\begin{abstract}
This paper aims at providing a comprehensive outlook on the economic and organisational rationale of $3 \mathrm{D}$ printing technologies and their implications for innovation in the Italian manufacturing industry. Despite its limited impact on the industrial world, the idea of printing actual 3D objects has clearly captured the popular imagination; 3D printing is often linked to 'big changes' or to sometimes indefinite industrial revolutions in progress because it is considered that $3 \mathrm{D}$ printing will eventually enable 'mass customisation'. None of the most significant actual applications of AM in Italian manufacturing, however, suggests that any real 'manufacturing revolution' has started or can be foreseen in the near future for consumer goods. For these AM is neither competitive today, nor can it be made so in the future, unless some sort of technological quantum leap occurs.
\end{abstract}

Keywords: 3D printing; rapid prototyping; additive manufacturing; Italy; aerospace; biomedical; automotive; jewellery; designed for additive.

Reference to this paper should be made as follows: Beltrametti, L. and Gasparre, A. (2018) 'Industrial 3D printing in Italy', Int. J. Manufacturing Technology and Management, Vol. 32, No. 1, pp.43-64.

Biographical notes: Luca Beltrametti is Full Professor of Economics and Head of the Department of Economics and Business Studies at the University of Genoa, Italy. His current research activity concerns the economics of innovation, with particular regard to the digitisation of manufacturing.

Angelo Gasparre is an Associate Professor of Organisation and Human Resource Management at the Department of Economics and Business Studies of the University of Genoa, Italy. His current research interests include technology adoption, innovation and the digitisation of manufacturing.

\section{Introduction}

According to the World Bank (2016), in 2015 Italy occupied ninth position in the rankings of world industrial production by country and third position at the European level. Italy is therefore an important player in world manufacturing; its industrial structure is characterised by a huge preponderance of small- and medium-sized firms ${ }^{1}$, a significant and persistent tradition of industrial districts (see, e.g., Pyke et al., 1990) and it 
holds a major position in many technologically advanced sectors such as automotive, aerospace and packaging.

As regards additive manufacturing (AM), we can consider the cumulative numbers of industrial AM systems installed in each country from 1988 through to the end of 2014, provided by Wohlers Associates Inc. (2015). From this perspective Italy is again in the top ten and one of the five countries which hold a better position in the AM systems ranking (sixth) than they do in the ranking in relation to world industrial production (ninth) ${ }^{2}$. As in every other country, however, the scope of AM in Italy is still modest, and of course this comparison is rather imperfect ${ }^{3}$, but it provides a hint that Italy seems to be in the leading group of adopters of industrial AM systems at the world level.

Before we get into the details of the Italian landscape of industrial 3D printing, we should draw our attention to the technology itself and its development in recent years.

The creation of a CAD drawing and then the subsequent 'printing' of the object(s) it depicts (made of plastic, metal, ceramics, wax, gypsum plaster, etc.) is, in fact, still part of the experience of a number of operators (though the proportion of such operators is shrinking). These operators work either in the manufacturing industry (manufacturing and design, prototyping and 'rapid' production professionals) or in the world of 'makers' or 'Craftsmen 2.0' (Anderson, 2012; Gauntlett, 2011). They have received the latter soubriquet since huge expectations have been placed on them in terms of innovation and the spreading of new forms of the typical creative practices of craftsmanship. These two phenomena are associated, respectively, with the advent of professional top-level printers (for high quality plastics and for metals) and that of very cheap open access devices. The similar nature of traditional printers and these new technologies justifies the use of the term ' $3 \mathrm{D}$ printers' as a synonym of 'additive manufacturing': a production process that create objects (component parts, semi-finished or finished products), using a wide range of technologies, by generating and adding up successive layers of material, thus 'adding' rather than moulding, forging or 'removing' material (additive vs. subtractive manufacturing), as in many conventional production techniques (turning, milling, etc.).

3D printers, however, are not a recent technological innovation. In fact, their use in 'rapid prototyping' in support of the development processes of new products dates back to the eighties; the first 3D printer was created by 3D systems in 1984. Starting from the second half of the ' $90 \mathrm{~s}$, however, this prototyping technology spread significantly across many manufacturing sectors, and particularly across the automotive industry. And over the last few years it has been adopted in final production activities, having become the top choice in some areas of the aerospace, biomedical and automotive industries.

Even though AM applications have been constantly growing for many years, the size of this market is still rather modest. According to the 2015 edition of the Wohlers Report - the main source of data in this field since 1995 - the AM industry (all products and services directly associated with AM processes, both at the industrial and at the desktop level) reached $\$ 4.1$ billion turnover globally in $2014(+35.2 \%$ over 2013 and $+33.8 \%$ compound annual growth rate for the period 2012-2014), of which \$2 billion was for products (AM systems, system upgrades, materials, aftermarket production) and \$2.1 billion was for services (parts produced by service providers, system maintenance, contracts, training, seminars advertising, publications, consultancy). As is clear, this still is a rather negligible volume when compared to the value of manufacturing at the global level; this has reached approx. $\$ 11,600$ billion (World Bank, 2016). 
Despite its limited impact on the industrial world, the exposure of 3D printing has been impressive in recent years. The idea of printing things has clearly captured the popular imagination. This has been particularly so in Italy where there an important tradition of craftsmanship and strong cultural support of design, self-employment ${ }^{4}$ and creativity led activities. However, information about these aspects is often in the form of hearsay and rumours; we are missing reliable analyses in terms of AM's actual diffusion and realistic industrial potential.

With few exceptions, AM is almost always presented as a radical and remarkably important innovation that will be capable of producing deep changes in the world's economy and in society - from multiple points of view (Huang et al., 2013). With 3D printing, in fact, objects can be manufactured with almost no constraints in terms of geometries and this is expected to support big changes in the way things will be manufactured in the future, leading to increased efficiency in the running of production processes $^{5}$ and to new business models (Rayna and Striukova, 2016). Some even have used the persuasive (albeit rather abstract) label of 'mass customisation' (Tuck et al., 2008) which suggests that $3 \mathrm{D}$ printing will allow a different localisation the of production activities with different logistics becoming associated with on-demand real time production of spare parts, the reorganisation of labour, the creation of new professional skills in the area of manufacturing and the crafts, as well as the creation of new spaces facilitating individual's creativity. Some of these latter suggestions stand on insecure foundations; they are echoing the idea of 'big changes' still to occur in the near future and raise great interest in the manufacturing industries which are attracted by the benefits that could be obtained especially in small-scale applications and for pieces with a particularly complex geometry. As a matter of fact, AM techniques can be used to develop the strength of sectors in which economies of scale are not the main driver of success but where promptness and rapidity of action are the winning factor.

In this paper we aim at providing a reliable picture of industrial 3D printing adoption and its actual potential in one specific industrial domain: Italian manufacturing. This article, in fact, builds on an extensive field study of the country's manufacturing domain that we ran from 2013 to 2015.

In the next section, we present the methodology of the research. After this, another whole section is dedicated to framing an economic and organisational perspective on the subject. This part of the article is mainly based on a literature review but the interviews (mainly with technicians, R\&D managers and experts) have been vital for the understanding of the adoption properties and actual potential of this technology.

Section 4 (Industrial 3D printing in Italy) is the central part of the article and attempts to extensively present the research findings. The section is structured into seven subsections and covers the most relevant applications of 3D printing in the Italian manufacturing domain, both in prototyping and manufacturing, and notably in the aerospace, biomedical, automotive and jewellery industries as well as in tooling and other less relevant areas. For each application we provide case histories, discuss the relevance of this innovation and its future prospects.

In the concluding section we elaborate on both the literature and the research findings in order to provide a genuine contribution to the understanding of the actual role of $3 \mathrm{D}$ printing both in Italian manufacturing and beyond the Italian case. 


\section{Methodology}

The introduction of 3D printing into the industrial world, beyond prototyping, is very recent and limited data is available to support the different arguments. Scientific research on AM has been strongly focused at the technological level, so far, while awareness of the subject is still lacking in terms of its economic, strategic and organisational aspects.

Our research approach, then, has been to explore how Italian companies are actually adopting 3D printing technologies in their production processes, thus moving to the field level and discussing the comparative advantages and potential of AM as well as its limits with entrepreneurs and managers who are currently involved with this technology.

The interview partners for our research have been identified by adopting the snowball sampling technique (Heckathorn, 1997; Salganik and Heckathorn, 2004; Atkinson and Flint, 2004; Morgan, 2008); this is frequently used in social research within hidden populations or when a highly cooperative attitude on the part of interviewees is believed to be crucial to the gathering of reliable research data. Although the research population was not technically 'hidden' in this case, interviews were probing many delicate concerns as investments in technological innovation and non-disclosure issues were clearly involved. A frank and open stance by participants was therefore considered to be vital and, despite the multiple methodological bias of this non-probabilistic sampling technique, it proved itself to be an effective research method.

As for the research process, the first step was to get in contact with (AM) technology supplier companies and gather information about the technological developments which have occurred in recent years and how their major clients were integrating $3 \mathrm{D}$ printing into their business activities. Their collaboration has been vital, also, in enabling us to connect with early-adopters in the Italian manufacturing domain and to the service provider companies to whom they outsource the manufacturing of the $3 \mathrm{D}$ printed objects. In the early days of the research, we also interviewed a few representatives of the makers world and some other experts (researchers in engineering and materials and technology analysts).

In the course of the research, 48 in-depth interviews were carried out with: entrepreneurs and managers of (AM) technology supplier companies (6); early-adopters in the manufacturing domain (11); service-provider companies that specialise in AM (22); people of the makers world (3); and experts (6).

All of the interviews took place in the boardrooms of the enterprises where the informants worked and the interviews were of variable length: from about 40 minutes to more than 2 hours. Service-provider company interviews were recorded and carried out on the basis of common guidelines. Most of the others were recorded as well but not all, since some of the informants were uneasy about the procedure and we wanted to preserve the authenticity of the conversations. Also, no guidelines were adopted in relation to the interviews with technology supplier companies, early-adopter manufacturing companies, experts and people of the makers world.

\section{An economic and organisational perspective}

AM should be seen in the broader context of 'digital manufacturing' (Annunziata and Evans, 2013; Foresight, 2013; Brynjolfsson and McAfee, 2014), i.e., the phenomenon 
that, for decades, has integrated digital technologies with manufacturing by utilising computers with growing computation capacities and 'intelligence' to automatically control systems - 3D printers are a further evolution from CNC machines - and by sharing information (between machines, between people and between machines and people) thanks to the World Wide Web, including on mobile devices.

When innovation spans such a wide range of activities, it is not easy to estimate its actual economic significance or its strategic implications at corporate level. In their rapid evolution, AM applications have been bringing about some real benefits, but also they have engendered some generic and occasionally unrealistic expectations as the overall context puts strong emphasis on the potential breakthrough capabilities of these technologies - which have even been declared as heralding the dawn of a 'third industrial revolution' (Berman, 2012; Barnatt, 2013; The Economist, 2012), or even something that 'will change the world' (Campbell et al., 2011; D'Aveni, 2013; Lipson and Kurman, 2013).

Clearly, in such an enthusiastic atmosphere, we should be cautious when assessing the economic and organisational implications of an innovation that is certainly important, but should be studied in more depth over the next few years to separate its actual potential to create change from the rhetorical dimension of the myth that is already characterising the phenomenon. In fact, we must try to grasp the global effects of a plurality of innovative phenomena - from AM to robotics and the internet - together with a transformation in the types of relationships between corporations and customers which can exist, as well as the new propensity of the public to 'participate' and 'share' information, knowledge and know-how.

Scientific research, however, has been strongly focused at the technological level, so far, while awareness on the subject is still lacking from the economic, strategic and organisational standpoints. However, these aspects are today more significant than in the past since $3 \mathrm{D}$ printing applications are increasingly related to production rather than to the field of prototyping.

These developments concern many aspects of production management, such as the technical environment for the design process, the space which is thus facilitated for human creativity, the management of stocks and changes in materials. These issues are interesting and open up the possibility of potentially disruptive innovations in the management of production and at the organisational level: we cover these aspects in Section 3.1. The idea of printing 3D objects, however, is clearly arousing expectations of bigger changes, involving the very structure of production at the macro-level. Seductive labels are often used to promote these ideas, and 3D printing is sometimes juxtaposed with a hint at some new industrial revolution in progress, where 'everything changes' and 'mass customisation' is no longer an amusing oxymoron for marketing enthusiasts. We are clearly sceptical about these arguments and we devote to them a few remarks in Section 3.2.

\subsection{Thinking additive and its consequences}

One of the core features of AM is that it almost completely eliminates the technical constraints regarding the geometry of objects. This makes it possible to create goods with an intrinsically better technical and functional profile, resulting in higher performance or an increase in efficiency. 
This is evident, for example, in the production of parts to be used in thermal stress, which, consequently, need to have a built-in cooling circuit (Ferreira and Mateus, 2003; Rännar et al., 2007). With conventional technologies, a first option is to build the object by welding multiple parts together or, if a single block piece is needed, to create a plurality of (necessarily rectilinear) holes that meet to form an internal cooling circuit, where the intersection axes between the holes will form sharp angles. The latter, of course is not an excellent situation for fluid circulation. In contrast, with AM, single block pieces can be created that contain cooling circuits with curvilinear geometries designed to optimise fluid dynamics properties.

A second case is related to the possibility of using this greater construction freedom to obtain lighter pieces at equal physical resistance properties, a significant goal for a wide variety of application, typically in the aerospace industry where the weight savings appear to be paramount [according to Wohlers (2011), in fact, the reduction of $100 \mathrm{~kg}$ in the weight of an aircraft is estimated to give annual fuel savings of approx. \$2.5 million in airplanes used for short flights]. It is not surprising, then, that all of the big players in the industry are developing projects for the reengineering and manufacturing of many components with AM. This is, for instance, the case for Boeing, who produces equipment for the assembling of wing ribs in 3D. Airbus too makes some small supports for television screens which are built into the back of seats. These are constructed, via AM, as aluminium honeycomb structures, and this construction allows lighter and more robust pieces to be obtained compared to the previous solution that required the welding of multiple pieces printed with an injection methods. And generally, Airbus are said to be greatly expanding the range of its AM manufactured components ${ }^{6}$. The case of Avio Aero will be covered in details in the next section.

Finally, a third case illustrates the potential of the reduction of construction constraints, facilitated by AM, which allows the making of objects with better aerodynamic properties (Kumar et al., 2011) - a significant objective in all the areas where speed is a strategic factor (e.g., Formula 1, motorsports, etc.). This, in addition, yields benefits associated with energy efficiency improvements.

The greater freedom to obtain a wider variety of geometries is also associated with a reduction in the number of pieces to be assembled, which obviously expedites not only lower labour costs per product unit, but also, as in the case where traditional techniques require the welding of multiple pieces, higher levels of technical functionality: welds are not only expensive, but they add brittleness to the object.

However, besides these potential technical-functional benefits, there is another dimension of analysis that concerns the aesthetic profile (Hague et al., 2003) of the objects produced. Less construction constraints imposed on the creativity of the designer expands actual design options and contributes to the discovery of more beautiful, original, distinctive and personalised shapes. This can clearly offer many opportunities from a commercial point of view.

Since AM allows the manufacturing of intrinsically superior parts and products from a technical, functional and/or aesthetic point of view, it is consequently wrong to assess the possible uses of this technology exclusively by looking at the production costs of the same object made with additive as opposed to conventional techniques. Making an object in its current configuration, in fact, may cost more with a 3D printer, but it is the reengineering of its construction (the 'thinking additive' logic) that makes it possible to obtain greater economic benefits from adopting additive technologies. This is an essential point to consider: in traditional manufacturing fields (e.g., milling), the design activity 
incorporates the guiding principle that production specifications should tend to minimise 'removal' activities, according to the principle "the less material I remove, the less the product will cost". In the case of AM, on the contrary, the same aim, of maximising production efficiency, translates into creating designs which use minimal quantities of raw material, according to the principle "the less material I use, the less the product will cost". The constraints and opportunities inherent in the design and production processes therefore change when using the additive logic, and the greater economic benefits derive from the ability of manufacturers to rethink the design of objects in a way that best exploits the potential of this technology, according to new criteria.

Another line of analysis concerning the transformation of production processes towards AM technologies regards the introduction of changes in the materials used (Campbell et al., 2012). This implies phenomena of contrary natures. On the one hand, the use of these technologies allows for a considerable reduction in the consumption of raw materials, which may change the terms of comparison between the costs and benefits connected with the choice of manufacturing with more precious but better performing materials. On the other hand, being able to span varying construction geometries could induce manufacturers to use less precious and costly materials instead - if the reengineering of the artefact's architecture allows them to obtain the same high technical-functional performance parameters but with these 'lesser' materials. The original state of the materials used in AM differs from that of the materials used by traditional processes. In the case of metals, instead of ingots AM technologies use extremely fine powders (45-100 micron) that must be produced ad hoc and then processed with laser sintering or other techniques. In the case of plastics, AM requires the ad hoc production of specific controlled quality materials in the form of powders, resins or filaments. In this regard, it is important to point out that these conditions affect the overall amount of energy required, as well as the location where it is consumed. The net environmental impact of AM is not obvious. On the positive side, we have the consequences of a reduced use of raw materials (typically, in order to make an object weighing $1 \mathrm{~kg}$ with a melting process, approximately $4 \mathrm{~kg}$ of matter are needed, while approx. $1.1-1.5 \mathrm{~kg}$ is sufficient with AM), a greater efficiency in the logistics chain and a possible replacement of materials requiring energy-intensive production processes with other, low-impact, materials. On the potentially negative side, we should mention the fact that powder-melting processes consume much more energy per mass unit of raw material than do traditional processes. In traditional manufacturing processes, in fact, the logistics of materials includes a first stage, for the transport of raw materials (e.g., metal) to the place of production; a second stage, for the transportation of waste from the place of production to the disposal site and, if the production waste can be reused, a further transportation to the place of their reuse. By contrast, with AM, there is only a minimum amount of waste, which implies minimised economic and environmental costs in relation to waste processing. However, the production of metal powders requires more energy than the more traditional production of ingots, and this obviously affects the cost of the raw material (e.g., titanium costs from approx. $€ 90 / \mathrm{kg}$ for ingots to approx. $€ 190 / \mathrm{kg}$ for powders).

$3 \mathrm{D}$ printing is also expected to change the management of stocks and the associated logistical activities (Walter et al., 2004; Hasan and Rennie, 2008; Holmstrom et al., 2010; Foresight, 2013; Holmstrom and Partanen, 2014; Khajavi et al., 2014). Starting from a CAD file, AM allows for the creation of unique pieces or small series where and when 
one likes without the need to pre-arrange complex processes or preliminarily prepare specific ancillary artefacts (e.g., dies, imprint moulds, etc.). The rationalisation of stocks and the optimisation of internal logistics - the foundation of 'lean production' - would therefore find a powerful ally in AM techniques, since one can imagine that the need to retain stocks of spare parts may be significantly reduced if they can be printed 'just in time'. This is particularly true where the value of the pieces, as well as the urgency to produce them rapidly, are high, as, for example, in the aeronautical, but also in the automotive industry. In some cases, unit production costs might be higher with additive techniques than with traditional methods, but this higher cost could be more than offset by the savings permitted by stock management optimisation both in financial terms (a reduction in locked-up capital) and in connection with the potential reduction of the warehouse and logistical costs. According to White and Lynskey (2013) this may potentially lead to tremendous savings; one need only consider that an airplane can contain up to 4 million pieces.

\subsection{Industrial revolutions and beyond}

One of the reasons that explains the exuberance of those who evoke the start of a 'third industrial revolution' with the advent of AM (Berman, 2012; Barnatt, 2013) or the 'changing of the world' (Campbell et al., 2011; D'Aveni, 2013; Lipson and Kurman, 2013 ) is the heavy reduction of economies of scale: the production costs of a 3D printed object seem to be almost independent of volumes.

During each production cycle - which, in the case of metal, may last a dozen of hours or even more - a 3D printer can make a number of pieces varying from one to a maximum of hundreds, depending on the size of the pieces and on the build chamber of the printer. Economies of scale are very limited: with increasing production, total costs increase according to a substantially linear function (Atzeni and Salmi, 2012; Atzeni et al., 2013). Some nonlinearities can be observed, but they are very small for an individual machine, and rather limited even when a serialisation of multiple machines is used; they basically are related to the consumption of materials: for example, printers that use plastic materials cause a 'discharge' (of material, which is therefore wasted) after depositing each layer, which is independent on the number of objects to be printed. Even costs in terms of machine-hours show a 'stepped' trend with increasing amounts to be produced. To optimise the use of resources, the capacity of the machine must be saturated at each production cycle and machine use must be saturated within the span of 24 hours. The use of multiple machines in parallel reduces the labour unit cost (personnel required to set up the production cycle and collect the piece produced at the end of each cycle) and the unit cost for the procurement and maintenance logistics. The use of multiple machines can also allow one or more machines to be dedicated to the use of each material, thus reducing the costs (for machine cleaning and resetting times) to be borne each time the material used for printing is changed - where this is applicable.

So, to date, AM is not competitive, in terms of costs, for large-scale production. In any case, the absence of economies of scale becomes a very important strength in single-piece or small series production, as the costs of variants are virtually null: these costs only relate to the need to ensure that the variant is compatible with the specification of each production process: e.g., that it does not violate any size constraint, thus forcing the manufacturer to produce less pieces during each production cycle. This is because any revision or adjustment can be made on the construction drawing (in the CAD) and 
implies no need to reset and/or retool the equipment, or, most significant of all, to prepare new moulds: these latter typically involve high production costs, take time and are justified only when the goal is large-scale production. So, from this point of view, the use of AM challenges the traditional idea that there is a trade-off between cheap mass production, which benefits from economies of scale, and high-cost customised production (Foresight, 2013).

If economies of scale are doomed to be of less importance in the future of manufacturing, then this is good news particularly for small and medium size enterprises and therefore for the Italian industrial sector, as it involves a dramatic resizing of the risk component implicit in the requirement for a guarantee of a 'minimum lot' capable of justifying investment in innovation. In addition, if the importance of economies of scale is reduced, the economic barriers to the entry of new enterprises in markets traditionally closed to small and medium-sized organisations will be lowered. Furthermore, AM probably uses a less specific capital stock (i.e., less specialised machinery) - a condition that, if it proves true, will increase the inter-exchangeability of capital stock between different industries and possibly expand the use of contract manufacturers. This latter would result in the reduction of the costs of the launch of new products and so would make it simpler and less expensive to transition from an initial project idea to its marketing. This considerably decreases the risk level involved in such an investment. The maker can also test the reaction of the market by initially using small-scale production before making greater investments.

The idea that there are 'no economies of scale' in AM, however, is catching on to the extent that many observers of the 'revolution of 3D printers' consider that this will make it possible to radically restructure the manufacturing industry towards local small-scale and high-quality production, thus creating a future wherein large enterprises would disappear and mass production would become only a memory of a past era of industrial development.

On the other hand, whatever the view of these 3D printing enthusiasts, there is no trace of any such transformation process to date (see the next section). It is certainly true, however, that the huge volumes of data available to big data companies on the tastes and behaviours of customers, combined with the possibility to directly interact with them through the internet, is an important factor in any assessment of the potential of AM. The basic idea would be to integrate/transform the typical organisational processes of mass production in the light of the World Wide Web and 3D printing's potential in terms of product customisation based on the tastes, needs and specific propensity to 'participate' of consumers. Some marketing literature, in fact, does make mention of the many experimental trials made by some important manufacturers of consumer goods, such as Levi Strauss's, Nike and Swatch, interested in AM processes for the customisation of products (Reeves et al., 2011). These experiences, however, are very limited so far and there is no sign of any activity leading to concrete applications of a larger scope in the near future.

The greater competitiveness of small-scale production, the very low degree of labour intensity and the moderate environmental impact of AM also suggests (European Commission, 2013) that a lower spatial footprint of manufacturing facilities would be possible in the future and a relocation of manufacturing sites nearer to consumption areas - even to within urban centres. But the issue of the role of the economies of context, typical of clusters and districts, in relation to this new technological scenario remains 
open. The development of AM could therefore reduce the incentive to delocalise to low labour-cost emerging countries, considering that the labour factor would have a lower incidence on the total cost, the cost of raw material would remain substantially unchanged and the lesser environmental pollution problems associated with 3D printing would reduce the importance of the competitive advantages of countries with less restrictive environmental regulations. All in all, according to the literature, 3D Printing should support a redefinition of supply chains, which are global today, towards regional connection relationships between less structured enterprises with a lower degree of sequential interconnection. The signs of such developments, however, are hard to find at the moment.

While these remarks take on a positive meaning for the economies of Western countries, the implications of such a change on employment must be considered as well. The production processes that would eventually be re-imported in countries, given this greater degree of development, might be extremely rich from a technological viewpoint, but would require incomparably lower labour intensities compared to those that characterise traditional manufacturing (Brynjolfsson and McAfee, 2014) - a situation that would generate doubts about the social consequences of new hyper-technological production paradigms.

The development of AM also raises new juridical issues associated with the protection of intellectual property. This subject is being extensively discussed today due to the increasing difficulty in ensuring such protections with the digitisation of production processes. In the specific case of AM, it is particularly hard to identify violations and to set a neat border between what is a lawful repair and what is an unlawful 'reconstruction' (Wilbanks, 2013). Furthermore, the advent of affordable 3D scanners makes the practice of reverse engineering more common and this raises further juridical issues. Indeed, the scan generated point cloud data of a given object is what is transformed into a STL file (the kind of file that a 3D printer can handle) - by using a specific software: this process makes even more complex the identification of the border between legitimate behaviour and infringements in intellectual property rights (Kurfess and Cass, 2014).

The absence of economies of scale reduces the automatic protection that can be achieved through the cost structure and makes legal protection of intellectual property even more important. In general terms, the usual dilemma about patent protection remains. On the one hand, strong protection is an incentive to more research and development efforts and to bigger investments; on the other hand, technological progress is also generated via hybridisation and the incremental improvement of previous innovation. The latter factor results in a collective interest in milder forms of protection (Boldrin and Levine, 2013).

\section{Industrial 3D printing in Italy}

The most significant applications for 3D printers in Italian manufacturing can be seen not only in the consolidated field of rapid prototyping but also in the direct production of parts for final use in the aerospace industry (the plant of AvioAero in Cameri is the largest factory in the world conceived solely for AM) and in the biomedical industries (Lima Corporate is a leading company in the manufacturing of the so called 'acetabular cups' used in hip implants). In these two sectors, in fact, Italy is actually a global leader in the use of AM. Other relevant applications are in the automotive industry (both for 
prototyping and for direct production - the latter mostly in the racing sector), in the dental industry (which is just beginning to embrace this new technology) and in the jewellery sector as $3 \mathrm{D}$ printing has now been adopted in the production of models produced by direct lost wax casting.

\subsection{Prototyping}

Additive technology has almost three decades of history in Italy in the field of industrial prototyping. The first applications, in the late eighties and nineties, were seen in the automotive industry within Ferrari, Fiat, Lamborghini and Ducati, this latter being one of the informant partners in our research. Although the phenomenon has not been extensively covered in management research, the additive technologies have certainly contributed significantly to the bringing about of a revolution in the development of new products (Onuh and Yusuf, 1999) as they have caused the time required to renew product lines to reduce from 36/40 months to only 18 months for a car: a result that has sparked very important changes in corporate strategies and marketing, as well as in the organisation of labour in the industrial world. This has been made possible, essentially, due to innovations in industrial design (the adoption of CAD systems), but the possibility of building physical prototypes within very short timescales with the use of 3D printers has given significant momentum to this progress.

Notwithstanding the impressive advances in 3D simulation software, our informants confirmed that prototyping is still considered to be essential to eliminate design errors that may become clear only during application. In addition, prototyping is a crucial process which provides real tools for internal and external marketing actions, as well as for the early training of workers before the actual production starts. Prototyping is also important in negotiations with part suppliers: the availability of a physical prototype reduces problems caused by ambiguity in construction drawings (even when made with CAD systems), and consequently the need for the supplier to take precautions by charging higher prices due to the risk of unforeseen complexities in the construction of the piece.

Thus, the use of 3D printers has provided many advantages: in the first place, a significant reduction in prototyping times (and consequently in design times) and a reduction in the cost of models. In the past, in fact, it was the model maker's task to manage the transition from the construction drawing to the model (e.g., one made of wood). With 3D printing, however, this transition phase is no longer necessary. This last advantage has allowed for a significant expansion in prototyping - which now includes, in many cases, all the components of a complex object. In the automotive industry, in fact, every single part of an engine is now prototyped.

However, not all technological innovations in the field of rapid prototyping are the result of the adoption of AM. A number of important industrial organisations still use CNC machines or moulding to manage the transition from the CAD drawing to an actual object - which is often made by fusion. Even this conventional approach, however, can benefit from important productivity increases associated with the use of digital technologies: software that automatically produces cost estimates in real time to the customer, who can simply download a CAD file of the object to be built from the internet; the exploitation of economies of scale by concentrating production (and, therefore, the recycling of materials) in a single large manufacturing site connected with 
customers via the internet; and very rapid product delivery times. Using this conventional approach, it is possible for prototypes or the final goods to be produced in numbers usually not exceeding 10,000 units with innovative materials that AM cannot manage (e.g., glass or carbon fibre reinforced plastics).

\subsection{From prototyping to manufacturing}

The news, in more recent times, is the growing importance of the use of industrial 3D printers in the production of parts and components for final use. On the whole, the Wohlers Associates Inc. (2015) estimates that modelling and prototyping ('visual aids', 'presentation models', 'fit and assembly models') account for only $36.8 \%$ of all applications, and this shows a dramatic increase in final parts production over the last few years (in 2008, final part production accounted for less than 12\%). However, the situation is very different in metal as opposed to plastic AM production since prototypes account for only approx. $20 \%$ of metal products produced, but approx. $80 \%$ of plastic products (Wohlers Associates Inc., 2013).

Although the relationship between prototyping and production is still definitely unbalanced in the favour of the former, it is in 'live' production applications that AM is today expressing its potential in terms of introducing ground breaking paradigms into the traditional manufacturing scenario.

The three sectors in which additive technologies have replaced traditional technologies and have today become the primary technological practice adopted in the Italian manufacturing domain are the aerospace industry, for the production of parts of aeronautical engines; the biomedical industry, with a special focus on the production of prosthetic aids in the orthopaedics, orthodontics and hearing aids areas; and finally in the production of parts for the motorsports industry. The president of General Electric Aviation has recently declared that, thanks to AM, in five years it will be possible to produce an engine weighing 1,000 pounds less than those of today. This is of particular interest for Italy since, as we have said, both in the aeronautical and biomedical industries, the country is a global leader in the use of AM.

The most significant applications for AM in these three industries are all closely linked with the production dynamics and economic characteristics of titanium, which is used to make turbine blades and other components of aeronautical engines; the components of engines and other parts used in the racing industry; and in most orthopaedic implants and dental prostheses. In contrast, for hearing aids, AM applications concern specifically the so-called 'shells' (that contain the electronic components of the prosthesis), that are custom made in plastic materials based on a CAD scan of the auditory canal of each individual patient.

\subsection{In the aerospace industry}

In the aerospace sector, a particularly important case for the adoption of 3D printing in the Italian manufacturing industry is that of Avio Aero, another informant partner for our research. The company was founded by Fiat in 1908; its activities started together with the development and production of the first aeronautical engine - SA 8/75 - derived from a racing car engine. Avio Aero, however, is now a GE Aviation business and is the leader in the design, production and maintenance of mechanical transmissions and low-pressure 
turbines for the aeronautical industry; it is present on four continents. Italy is home to the head office, as well as plants based in Turin, Cameri, Pomigliano d'Arco (Naples) and Brindisi. The company has approximately 4,700 employees worldwide (4,000 in Italy and the remainder in Poland, Brazil and China).

The case of Avio Aero is particularly significant for 3D printing research since, at the Cameri plant in the aerospace district of the Piedmont Region, low-pressure turbine blades and other components of aerospace engines are exclusively produced using only AM. This feature makes the Cameri plant a unique case globally as it is the largest factory in the world conceived for $\mathrm{AM}$ and designed for the use of $3 \mathrm{D}$ printing at an industrial scale. The plant, in fact, can house up to 60 industrial 3D printers and is equipped for the functioning of two atomisers for the internal production of fine powders comprised of special metal alloys such as titanium aluminide (TiAl) and two systems for the thermal treatment of the components produced.

The strategic decision, of Avio Aero, to internalise the production of powders is unique in the global aerospace industry, as the leading manufacturers such as Boeing and Airbus did not take this further step; however, the cost of inputs certainly is one of the most critical aspects of AM today, which dictates the controlling influence of 3D printer producers on the raw materials market. Avio Aero, however, has developed metal powders using a broad range of alloys of steel, cobalt, nickel and titanium-based materials for different technologies such as laser metal deposition, selective laser melting and electron beam melting, thus revealing a possible decision to perhaps market these products in the future, externally, and not just to fuel its own production processes.

The most relevant application of AM, to date in the Cameri plant, is the production of turbine blades for aluminium-titanium alloy jets with thermodynamic performances equivalent to those made with traditional materials, but with a weight reduced by $50 \%$ and $50 \%$ lower costs. Fewer design constraints, in fact, have made it possible to build forms with more robust structures using less material. With AM, the body of these objects can be reduced by adding reticular support substructures with special performance levels as to physical resistance and/or ribs with particularly complex geometries. Also, weight reduction is associated with benefits in terms of production related energy consumption, since less energy is required for the handling of these pieces. Moreover, all the materials that are not melted can be quickly reverted.

Another very critical issue that can be clarified by looking at the production processes that take place in the Cameri plant of Avio Aero is that of the quality of products. Electron beam melting, in fact, allows the company to overcome the limits of investment casting of titanium-based materials. The final product has similar and potentially better metallurgical properties than components created using investment casting. Using this method, it is also possible to obtain much thinner walls (of $1-1.5 \mathrm{~mm}$ ) than can be achieved through conventional casting techniques, as well as being able to create free-form geometric shapes.

An example of what the great design freedom of AM can provide in relation to aerospace production processes can be understood by looking at combustor injectors. This part if made by casting is produced with five pieces which then need to be joined together, while with AM technology only one piece needs to be produced. Moreover, to make a product weighing $1 \mathrm{~kg}$ using casting more than $4 \mathrm{~kg}$ of material is needed while this requirement is reduced to $1.5 \mathrm{~kg}$ by adopting AM. 


\subsection{In the biomedical industry}

In the biomedical sector, AM allows for both customised single-piece production based on the customer's specifications - where the main applications are in the fabrication of dental, maxillofacial and cranial implants - and for the production of specifically sized pieces, particularly acetabular cups used for the construction of hip joint replacements.

For implants, in the case of single pieces, the determinant for the use of AM technologies is the possibility of achieving a complete customisation of the artefact, starting from a CAT or MRI scan. As we have said before, AM minimises the cost of variants and each 3D printer can simultaneously make multiple different products, subject to the sole limit of the overall capacity of the working airspace.

Similar remarks can be made regarding the custom-made manufacturing, with plastic materials, of the 'shells' for acoustic devices and models for specific orthopaedic conditions (e.g., fractures). These last plastic models reproduce the internal situation for orthopaedic surgery and are used by the surgeon to plan the procedure, to obtain the patient's informed consent and for teaching purposes. More specifically, planning surgery on a 3D model allows the reduction of procedure times to the benefit of both the patient and the healthcare facility. From the patient's point of view, in fact, the preparation of a surgical procedure with a physical 3D model will reduce the length of the anaesthesia and typically cause less bleeding. Surgery will be less invasive because a smaller operating field is defined. In its turn, the healthcare facility will be able to increase its production capacity (higher number of procedures per unit time) and ensure a better management of professional risks; the improvement in the overall operating performance obtained with protocols defined for the use of this technology has also been proved by the fact that in some countries (e.g., Switzerland) surgeons who use these protocols can pay lower third-party liability insurance premiums.

In the case of hip replacement, prostheses can be produced in different sizes based on predefined models, thus allowing for the modularisation of production in small lots. In this case, the determinant for the use of AM is not customisation, but the possibility of producing an artefact with physical properties that could not have been obtained otherwise. The special structure and degree of porosity of the metal material that can be obtained with additive technologies favour the integration of the implant into the patient's bone, which will grow around the acetabular cups made by 3D printers.

One of the leading companies adopting additive technologies in the Italian dental industry is LaStruttura Spa. The enterprise, whose representatives have been interviewed by the authors, was founded in 2003 and is involved in the production of dental restorations; the company is a $3 \mathrm{M}$ partner and is an official dealer for 3Shape Scanner ${ }^{\mathrm{TM}}$. The company produces their dental restorations by processing 3D data with rendering technologies that enables them to devise realistic digital simulations of the aesthetic results which could be obtained with the available different restorative techniques. One of the core provisions within LaStruttura is the integration of both additive and stock removal machining technologies. Their range of CAD/CAM solutions, in fact, has been steadily expanded over the last few years and they now specialise in the production of dental implants using the most innovative digital technologies and the most advanced milling, sintering and additive production devices. Production, in fact, starts with the receipt of the impression, then of the analogue datum, which is digitised and made available for the CAD-CAM systems: on one the hand, the tool paths for the milling machines are processed, but in parallel, realistic simulations of the aesthetic and 
functional results attainable are carried out before the product is implanted. In their plant at Cassano Magnago (Varese), mutually complementary professional staff integrates a broad range of competences: there are CAD 3D designers and digital impression specialists; dental technicians; electronics and computer specialists; and mechanics, among others.

The use of AM for the production of dental implants is heavily contributing to reshaping the condition of competition within this market as it allows for the reduction of construction times of implants from about 1 month to 2 days; the next step is likely to be the dispersion throughout the industry of $3 \mathrm{D}$ scanning systems for the generation of digital three-dimensional models of the oral cavity of the patient so that the last analogue phase in the product development process of dental restorations, the plaster impression, can be eliminated. All in all these innovations are certainly going to spark important changes in corporate strategies and marketing in this industry in the next few years and the Italian market is very important both in terms of clinical practices and for restorative aesthetics. Every year one and a half million titanium screws are implanted as replacement of teeth roots and $\mathrm{CAD} / \mathrm{CAM}$ solutions are particularly interesting for the production of these items. The adoption of additive technologies brings about innovative and customised solutions for restorative aesthetics too, as new printable dental ceramics have been developed in recent years.

Another very interesting application of AM in the Italian biomedical industry has been developed by another informant partner of our research: Lima Corporate, a global medical device company specialising in the designing, developing, manufacturing and marketing of orthopaedic replacements and repair solutions such as implants for the hips and knees. The company, controlled by AXA Private Equity and Intesa Sanpaolo since September 2012, has a deeply rooted Italian history as it was founded in 1945 by Carlo L. Lualdi in Villanova di San Daniele del Friuli (Udine) when he started production of surgical instruments. Titanium machining, however, began a few years after this as the founder's son, Gabriele Lualdi, became the company's CEO in 1968. In 1978, cooperation with an important orthopaedic surgery institute in Udine led to the first orthopaedic patents. During the eighties, however, a strategy of diversification was undertaken and the company entered the aerospace, automotive and mechanical products industries. As for orthopaedics, it certainly remained one of the company's markets, but in 2000 it became the company's only business, as they embraced additive technologies for the development of 'Trabecular Titanium" ${ }^{\mathrm{TM}}$, 3D printed microstructures and their acetabular cups gained global leadership in the hip implants market. Electron Beam Melting technologies, in fact, allowed the production of this advanced cellular solid structure with a single density gradient that can be used as a scaffold to regenerate damaged bone tissue with superior osseointegration properties, a critical feature for long prosthesis survivorship. The macro-porous structure of Lima's acetabular cups, in fact, generates an extremely high coefficient of friction, furthering the mechanical interlocking between the implant and the surrounding natural bone; also the free-form nature of 3D printing allows for the production of customised implants, without any constraint.

\subsection{In the automotive industry}

In the motor-racing industry, AM has a wider field of application than in the mainstream car and motorbike production industry. The research material for this section has been 
composed mainly by focusing on the experiences of Ducati. Relevant information, however, has been collected from many service provider companies that specialise in AM and operate in the automotive industry. The need to obtain complex geometries is typical of this field and budget constraints are not such as to make the cost factor a determinant. So the potential benefit of reducing budget constraints that characterises AM allows for the fabrication of custom-made artefacts that can be adapted to the ever-changing design requirements of the racing departments, in order to achieve specific objectives in terms of improvements in the vehicles' performance in competitions. There are multiple applications both using plastic materials and in the design of metal engine components, as well as for the other parts of the vehicles. One particularly interesting and innovative application is the AM of plastic forms (spindles) around which a carbon structure is built: plastic is dissolved with the appropriate solvents to obtain a seamless hollow carbon shape (for example, an air conduit with an aerodynamic shape).

Another field of application for AM in the automotive sector is in the production of top range cars and motorbikes, where small series of objects are being produced with characteristics that cannot be obtained using traditional techniques (e.g., pieces with integrated cooling circuits with excellent heat and fluid dynamic properties) or that are customised on the basis of the specific requirements or aesthetic tastes of customers. Finally, one further field is the production of spare parts for vintage cars and motorbikes (where, usually, a CAD file of the piece to be created must be previously prepared or generated ad hoc with reverse engineering).

In other areas of the automotive industry, AM has less specific fields of application. There are applications that might be appropriate also in other areas of industry, but which have been particularly developed in the automotive industry because it is in that industry that $3 \mathrm{D}$ printers have been used to a significant extent in prototyping. Thus, in the automotive industry, it has been more natural to open up to new ideas in relation to AM, even in fields which are more or are directly related to production.

An important use of AM in the automotive industry is for the production of tools to be used on vehicle assembly lines. These can be tools for assembling special parts or components, terminal pieces of the robots used to handle the parts (e.g., easily dented parts of the bodywork to be painted) or other types of tools that differ for each new model, so, with AM, they can be manufactured in a short time and at a relatively contained cost.

\subsection{In the jewellery industry}

Another interesting application of additive technologies in the Italian manufacturing system is found in its jewellery industry; Italy is the seventh largest exporter of jewellery in the world (Istat, 2013).

One of the leading companies in the Italian jewellery industry which is promoting the use of additive technologies is another informant partner of our research: DWS Systems, Digital Wax Systems, which is also the most prominent Italian 3D Printer producer. The company was set up in Vicenza in 2007 after a consolidated experience in 3D prototyping and it is now divided into four business units: jewellery, dental, general applications and consumer goods. They specialise in stereolithography technology and manufacture all the necessary resins and materials for additive processes.

DigitalWax ${ }^{\circledR} J$ is DWS's business unit for the jewellery industry. They have developed seven prototyping and rapid production systems specifically for the jewellery 
industry; these are capable of producing from a minimum of 10 to a maximum of 3,200 models a day. All the materials are produced in-house by DWS: casting resins, moulding resins, biocompatible nanoceramic resins.

Except for personalised jewellery pieces, which are handcrafted, most pieces are executed by casting machines. The initial input of these production processes is of course a three-dimensional design of the piece's concept which is in turn the output of a close cooperation process taking place between designers, who imagine the object, and model makers, who create the masterpiece of each piece. Once that the 3D design is completed a high-technology master mould is required in order to make wax reproductions of the piece through a casting process. The wax replicas of each piece of jewellery are placed in steel containers which are then filled with an investment powder and then heated. As the powder solidifies it melts the wax so that a liquefied metal can be poured into the flasks, which in turn is cooled to a solid and finally removed, so that the jewel can be filed, polished and eventually decorated.

3D Printing can play a significant role in the jewellery industry as it can be adopted both in the direct lost wax casting of jewellery models as a substitute of investment casting techniques and for the direct production of 'digital jewellery pieces', a new and promising market within this industry.

\subsection{Tooling and other applications}

Whereas the aerospace, biomedical and automotive industries are today the fields of choice and the most important areas for 3D printing industrial applications, other AM development perspectives nevertheless do appear in many other production areas characterised by limited scales and frequent product innovation. Various sector experts maintain that there are two industries in particular that show these characteristics and are, moreover, centres of excellence within the Italian manufacturing scenario: the packaging and the hydraulic pump production industries.

In the packaging industry, whose applications span virtually every production area from food to tobacco, medicinal products, and more - the so-called 'final manipulators' attached to machines, that put products into packages, need to be adapted to each new product or solution. Also there are the different templates required for the thermoforming of plastic containers. In these cases, with AM, not only can the required artefacts be built more rapidly and at a lower cost, but the packaging systems can be reengineered to be more flexible. One of the most prominent developments in the adoption of AM technologies within this industry has been undertaken at the R\&D department of Tetra Pak in Modena (Italy). As their representatives stated to the authors, they obtained a substantial reduction in the operating costs of their systems by building, with AM processes, several types of hot air blowing nozzle used to weld packages. The possibility of creating the printed circuit boards of the blower with different geometries by using the free form feature of AM allowed the manufacturer to optimise fluid dynamics and obtain a more uniform temperature along the welding line. This meant that the temperature of the air delivered by the blower could be reduced, and this facilitated significant energy savings.

Another interesting and, indeed, pioneering industrial application of AM is that which has been implemented by Bticino, the leading electrical equipment company. Bticino has been part of the French Legrand Group since 1989 but its history has been embedded in 
that of the Italian industrial culture since 1936, when it was founded in Varese, where they still have their main office and plants.

As they declare on their website: "BTicino was the first Italian manufacturer to tackle the problem of producing electrical components in the light of modern design thinking" (http://www.bticino.com/company-profile). Their pioneering experience of AM, in fact, has its origins in the early nineties in the search for more efficient injection moulding tools with conformal cooling channels. The conventional injection moulding process required the use of metal moulds that were manufactured with traditional milling method. With AM, these moulds were improved by introducing an internal cooling circuit with an optimised geometry from the point of view of thermal fluid dynamics. Each mould today costs slightly more than they did in the past, but the optimisation of its internal structure has allowed for a remarkable improvement in their production line performance. This is because the mould forming cycle has been significantly reduced, in fact, virtually halved.

Several experts that we interviewed mentioned the fact that in hydraulic pump manufacturing, where Italy is a global leader, it was found that the demand for flexibility could be fulfilled by AM. Production in this field is characterised by the need to make metal pieces with complex geometries that are typically obtained by assembling multiple components. In addition to this, the demand is increasingly moving away from the requirement for the large lot production approach towards reduced-scale productions with geometries that need frequent changes and therefore require continuous product reengineering.

A final general field of application concerns specialised outsourced processes that today, thanks to AM, can intercept the demand of companies from the most varied industries due to unexpected delays in the supply of standard pieces made with traditional techniques. An interesting and recent case, in this regard, concerns an important car manufacturer who, risking having to be forced to stop the production line due to a delay in the supply of a small metal object to be fitted into the engines, decided to outsource its 'rapid production' (at a cost which was more than ten times higher than the cost of the piece as produced with standard technologies) to a company specialising in AM services. The old idea of outsourcing work to avoid production stops, therefore, finds a new application in AM and the 'just in time' logic becomes more robust if an alternative solution exists to the delay in the delivery of a component.

\section{Conclusions}

In this paper, we aimed at exploring how Italian manufacturing companies are actually adopting 3D Printing technologies in their production processes, thus providing an original contribution to the debate on the comparative advantages and actual potential of AM. We gathered the voices of entrepreneurs and managers who are actually involved with this technology.

Our research confirms that additive technologies are attracting great interest among manufacturing companies; these are attracted by the benefits that can be obtained, particularly in small-scale production applications and for pieces with a particularly complex geometry. This innovation is particularly interesting for the Italian manufacturing industry, which is characterised by a high prevalence of SMEs that have 
proved very good at competing in small niches. AM, in fact, develops the strengths of the sectors where economies of scale are not the main success driver, but where promptness and rapidity of action and high efficiency are the winning factors instead. Furthermore, Italian firms are traditionally good at introducing incremental product design improvements and innovations aimed at making production processes more efficient.

For almost 30 years, 3D printing was solely adopted in Italian manufacturing as a tool for rapid prototyping, and it is just recently that technological developments (and tremendous cost reductions) have enabled their use for tooling and direct manufacturing of consumer products. To date, the most significant applications of 3D printers for industrial use in the Italian manufacturing industry can be seen either in the consolidated field of rapid prototyping, in the direct production of parts for final use in the aerospace industry (the plant of Avio Aero in Cameri is the largest factory in the world conceived for AM) or in the biomedical industries (Lima Corporate is a leading company in the manufacturing of the so called 'acetabular cups' used in hip implants). In these two industries, Italy is a global leader in the use of AM. Other relevant applications can be seen in the automotive industry (both for prototyping and in direct production, in the racing sector), in the dental industry, which is just beginning to embrace this new technology, and in the jewellery sector as 3D Printing is now adopted in the direct lost wax casting of jewellery models.

These developments are promising, but none of them suggests that a 'manufacturing revolution' with widespread impact and a significant influence in GDP terms is under way. In particular, this seems to be true for consumer goods - for which AM is neither competitive today, nor can it be in the future, unless some sort of technological quantum leap is made. Also, no major changes have been reported in the supply chains structure of the manufacturing industries which can be related to AM.

Furthermore, it must be recalled that:

- in most cases 3D printed components need to be refined through further post processes in order to obtain the required finishes

- even the fastest 3D printing process is typically hundreds or thousands of times slower than a conventional industrial process

- often reliable new testing methods, specifically applicable to AM, must be determined

- sometimes even the professional top end quality 3D printers make components that exhibit lower mechanical performance and durability than similar components made by traditional techniques thus preventing their application for structural parts.

For all of these reasons, it is likely that the adoption of 3D Printing will not be able to substitute conventional technologies, while integrated processes will presumably become increasingly important in the near future. For countries like Italy, however, a more extensive adoption of AM systems must surely appeal to SMEs. These enterprises, though, seem rather hesitant at the moment, and one might wonder whether the great 'hype' concerning the 'revolution of 3D printing' is perhaps obstructing rather than facilitating this process. 


\section{Acknowledgements}

We wish to thank the three anonymous referees for their careful reading of the early version of our manuscript and their useful comments and suggestions.

\section{References}

Anderson, C. (2012) Makers. The New Industrial Revolution, Crown Business, New York.

Annunziata, M. and Evans, P. (2013) The Industrial Internet@Work, General Electric.

Atkinson, R. and Flint, J. (2004) 'Snowball sampling', in Lewis-Beck, M.S., Bryman, A. and Liao, T.F. (Eds.): The Encyclopaedia of Social Science Research Methods, pp.1044-1045, Sage, Thousand Oaks, California.

Atzeni, E. and Salmi, A. (2012) 'Economics of additive manufacturing for end-usable metal parts', The International Journal of Advanced Manufacturing Technology, Vol. 62, Nos. 9-12, pp.1147-1155.

Atzeni, E., Iuliano, L., Marchiandi, G., Minetola, P., Salmi, A., Bassoli, E., Denti, L. and Gatto, A. (2013) 'Additive manufacturing as a cost-effective way to produce metal parts', Bartolo, P.J. et al. (Eds.): High Value Manufacturing, pp.3-8, CRC Press, GBR.

Barnatt, C. (2013) 3D Printing. The Next Industrial Revolution, ExplainingTheFuture.com, Nottingham.

Berman, B. (2012) '3-D printing: the new industrial revolution', Business Horizons, Vol. 55, No. 2, pp.155-162.

Boldrin, M. and Levine, D.K. (2013) 'The case against patents', Journal of Economic Perspectives, Vol. 27, No. 1, pp.3-22.

Brynjolfsson, E. and McAfee, A. (2014) The Second Machine Age, W.W. Norton \& Company, New York; London.

Campbell, I., Bourell, D. and Gibson, I., (2012) 'Additive manufacturing: rapid prototyping comes of age', Rapid Prototyping Journal, Vol. 18, No. 4, pp.255-258.

Campbell, T., Williams, C., Ivanova, O. and Garrett, B. (2011) Could 3D Printing Change the World? Technologies, Potential, and Implications of Additive Manufacturing, Strategic Foresight Report, October, Atlantic Council.

D'Aveni, R.A. (2013) '3-D printing will change the world', Harvard Business Review, Vol. 91, No. 3, p.34.

European Commission (2013) Factories of the Future. Multi-Annual Roadmap for the Contractual PPP under Horizon 2020, European Commission.

Ferreira, J.C. and Mateus, A., (2003) 'Studies of rapid soft tooling with conformal cooling channels for plastic injection moulding', Journal of Materials Processing Technology, Vol. 142, No. 2, pp.508-516.

Foresight (2013) The Future of Manufacturing: A new era of opportunity and challenge for the UK Project Report, The Government Office for Science, London.

Gauntlett, D. (2011) Making is Connecting, Polity Press, Cambridge.

Hague, R., Mansour, S. and Saleh, N. (2003) 'Design opportunities with rapid manufacturing', Assembly Automation, Vol. 23, No. 4, pp.346-356.

Hasan, S. and Rennie, A.E.W. (2008) 'The application of rapid manufacturing technologies in the spare parts industry', 19th Annual International Solid Freeform Fabrication Symposium An Additive Manufacturing Conference, 4-6 August, Austin, TX.

Heckathorn, D.D. (1997) 'Respondent-driven sampling: a new approach to the study of hidden populations', Social Problems, Vol. 44, No. 2, pp.174-199. 
Holmstrom, J. and Partanen, J. (2014) 'Digital manufacturing-driven transformations of service supply chains for complex products', Supply Chain Management: An International Journal, Vol. 19, No. 4, pp.421-430.

Holmstrom, J., Partanen, J., Tuomi, J. and Walter, M. (2010) 'Rapid manufacturing in the spare parts supply chain. Alternative approaches to capacity deployment', Journal of Manufacturing Technology Management, Vol. 21, No. 6, pp.687-697.

Huang, S.H., Peng, L., Mokasdar, A. and Hou, L. (2013) 'Additive manufacturing and its societal impact: a literature review', The International Journal of Advanced Manufacturing Technology, Vol. 67, Nos. 5-8, pp.1191-1203.

Istat (2013) L'Italia nell'economia internazionale, Rapporto ICE 2012-13, Istat, Roma.

Khajavi, S., Partanen, J. and Holmstrom, J. (2014) 'Additive manufacturing in the spare parts supply chain', Computers in Industry, Vol. 65, No. 1, pp.50-63.

Kumar, V., Makade, R. and Mehla, N. (2011) 'Advancement of rapid prototyping in aerospace industry - a review', International Journal of Engineering Science and Technology, Vol. 3, No. 3, pp.2486-2493.

Kurfess, T. and Cass, W.J. (2014) 'Rethinking additive manufacturing and intellectual property protection', Research-Technology Management, Vol. 57, No. 5, pp.35-42.

Lipson, H. and Kurman, M. (2013) Fabricated. The New World of 3D Printing, John Wiley \& Sons, Inc., Indianapolis.

Morgan, D.L. (2008) The SAGE Encyclopedia of Qualitative Research Methods, pp.816-817, Sage Publications.

Onuh, S.O. and Yusuf, Y.Y. (1999) 'Rapid prototyping technology: applications and benefits for rapid product development', Journal of Intelligent Manufacturing, Vol. 10, Nos. 3-4, pp.301-311.

Pyke, F., Beccattini, G. and Sengenberger, W. (1990) Industrial Districts and Inter-Firm Cooperation in Italy, International Institute for Labour Studies, Geneva.

Rännar, L.E., Glad, A. and Gustafson, C.G. (2007) 'Efficient cooling with tool inserts manufactured by electron beam melting', Rapid Prototyping Journal, Vol. 13, No. 3, pp.128-135.

Rayna, T. and Striukova, L. (2016) 'From rapid prototyping to home fabrication: how 3D printing is changing business model innovation', Technological Forecasting \& Social Change, January, Vol. 102, No. 1, pp.214-224.

Reeves, P., Tuck, C. and Hague, R. (2011) 'Additive manufacturing for mass customization', Fogliatto, F.S. and da Silveira, G.J.C. (Eds.): Mass Customization, Springer, London.

Salganik, M.J. and Heckathorn, D.D. (2004) 'Sampling and estimation in hidden populations using respondent-driven sampling', Sociological Methodology, Vol. 34, No. 1, pp.193-239.

The Economist (2012) 'The third industrial revolution', 21 April.

Tuck, C.J., Hague, R., Ruffo, M., Ransley, M. and Adams, P.R. (2008) 'Rapid manufacturing facilitated customisation', International Journal of Computer Integrated Manufacturing, Vol. 21, No. 3, pp.245-258.

Walter, M., Holmström, J., Tuomi, J. and Yrjölä, H. (2004) 'Rapid manufacturing and its impact on supply chain management', Proceedings of the Logistics Research Network Annual Conference, pp.9-10.

White, G. and Lynskey, D. (2013) Economic Analysis of Additive Manufacturing for Final Products: an Industrial Approach, University of Pittsburgh, Swanson School of Engineering, Mimeo.

Wilbanks, K.B. (2013) 'The challenges of 3D printing to the repair-reconstruction doctrine in patent law', George Mason Law Review, Vol. 20, No. 4, pp.1147-1181.

Wohlers Associates Inc. (2013) Wohlers Report 2013. Additive Manufacturing and $3 D$ Printing State of the Industry, Annual Worldwide Progress Report, Wohlers Associates, Inc., Fort Collins, Colorado. 
Wohlers Associates Inc. (2015) Wohlers Report 2015. 3D Printing and the Additive Manufacturing State of the Industry, Annual Worldwide Progress Report, Wohlers Associates, Inc., Fort Collins, Colorado.

Wohlers, T. (2011) 'Making products by using additive manufacturing', Manufacturing Engineering, April.

World Bank (2016) Global Economic Monitor.

\section{Notes}

1 In Italy the proportion of persons employed in non-financial business in firms with 0-9 and $0-20$ employees (respectively $46.4 \%$ and $57.4 \%$ ) is the highest in Europe (our elaborations from Eurostat).

2 Similar countries are the USA (first position in the AM systems ranking vs. second in the ranking in relation to world industrial production), Japan (second position vs. third), UK (fifth position vs. eighth) and South Korea (eighth position vs. tenth).

3 The Wohlers Report makes no distinction between AM systems using plastics and those using metals and does not take into account whether the machines are still in operation. This latter point should lead to an overestimation of the relative position of the early adopters of AM systems such as the USA.

4 In the Italian industrial sector, about $12 \%$ of occupied persons are independent workers, twice as many as in Germany and France (Centro Studi Confindustria elaborations on data by OCSE, Eurostat).

5 One of the most significant limits of 3D printers, however, is the size of the objects that can be built: to date, the maximum size for an object is around one cubic meter (for plastic objects), or less than half a cubic meter when the object is to be manufactured in metal.

6 The coming Airbus A350 XWB aircraft is set to be the most 3D printed plane in history, carrying over 1,000 plastic end parts (http://3dprintingindustry.com/2016/04/08/airbus-opensaerospace-3d-printing-factory-in-germany/). 